\title{
Endoscopic Transtracheal Approach for Tracheobronchial Surgery: Our Experience with This Novel Technique
}

\author{
Gautam Khaund ${ }^{1}$, Biswajit Gogoi ${ }^{2}$, Sanchita Kalita ${ }^{3}$, Keshavananda Konwar ${ }^{4}$, Utpaljit Barman ${ }^{5}$, Daisy Gogoi ${ }^{6}$, Partha P Bora ${ }^{7}$, \\ Nayan M Deka ${ }^{8}$
}

\begin{abstract}
Working field being the same, airway surgery becomes a challenging domain for surgeons as well as the anesthesiologists. In our study, we are highlighting the endoscopic transtracheal approach for tracheobronchial surgery (ETATS) as a novel technique to access tracheal and bronchial pathology. Diagnostic bronchoscopy and imaging aiding in preoperative planning, in conjunction with the anesthesiology team, this technique could aid in the management of airway cases, which might otherwise not be possible by conventional approaches. We have shared our experience with ETATS in three emergency airway cases as the outcome of management has been favorable.

Keywords: Bronchoscopy, Difficult airway, Endoscopic, Endoscopic transtracheal approach, Pulmonary hemorrhage, Tracheal mass, Tracheobronchial surgery, Transtracheal.

International Journal of Phonosurgery \& Laryngology (2020): 10.5005/jp-journals-10023-1188
\end{abstract}

\section{BACKGROUND}

Laryngotracheobronchial pathologies, particularly neoplasm, have often been diagnosed late because of their presentation as wheeze and being treated for a considerable time as asthma or bronchial hyperreactivity. ${ }^{1,2}$ Therefore, such cases usually present as an airway emergency requiring prompt decision for maintaining the cardiopulmonary reserve. Routine diagnostic bronchoscopy in patients with unresolved wheeze or airway problem can play an important role in early management of such cases. . $^{3,4}$ Therefore, a high index of suspicion is warranted in airway cases who might initially just present with symptoms mimicking asthma.

Airway surgery, in itself, is a challenging domain for surgeons as well as the anesthesiologists. ${ }^{3,5-7}$ Working field being the same for both the teams, limitations and compromises have often been met with. Surgeons frequently have to succumb to comparatively radical approaches like thoracotomy or sternotomy for tracheobronchial pathology. ${ }^{8}$ Though the minimally invasive bronchoscopic interventions have paved a niche for tracheobronchial surgery, we have faced avid limitations like crowded instrumentation and difficulty to secure the airway beyond the lesion. In order to overcome the issue of difficult instrumentation, securing the airway and relative ease in accessing the disease site, we have utilized a transtracheal endoscopic approach for some tracheal and bronchial pathology, which could not be removed by the orotracheal route. ${ }^{9,10}$ Moreover, the proximity of tracheal and bronchial pathology through the transtracheal route is worth mentioning. The ideal candidates for this approach are the neoplasms, pathology, or lesions limited to the tracheobronchial lumen.

In our cases, the decision of using the transtracheal approach has been made after thorough patient evaluation (clinical, radiological, bronchoscopic) in conjunction with the anesthetist team..$^{2,11,12}$ We would like to highlight the transtracheal endoscopic route as a convenient alternative to other approaches for therapeutic intervention of lesions limited to the tracheobronchial lumen.

The objective of our study is to highlight the technique of the endoscopic transtracheal approach for tracheobronchial surgery (ETATS). In our first case, we adopted the transtracheal endoscopic
${ }^{1}$ Department of ENT and Head and Neck Surgery, Nightingale Hospital and Pratiksha Hospital, Guwahati, Assam, India

${ }^{2-4}$ Department of ENT and Head and Neck Surgery, Pratiksha Hospital, Guwahati, Assam, India

5,6Department of Anesthesiology, Pratiksha Hospital, Guwahati, Assam, India

7,8 Department of Pediatrics, Pratiksha Hospital, Guwahati, Assam, India

Corresponding Author: Sanchita Kalita, Department of ENT and Head and Neck Surgery, Pratiksha Hospital, Guwahati, Assam, India, Phone: +91 9508867914, e-mail: drsanchitakalita@gmail.com

How to cite this article: Khaund G, Gogoi B, Kalita S, et al. Endoscopic Transtracheal Approach for Tracheobronchial Surgery: Our Experience with This Novel Technique. Int J Phonosurg Laryngol 2020;10(2): $40-45$.

Source of support: Nil

Conflict of interest: None

approach as a desperate measure in the management of an emergency case of tracheal mass. But eventually with its successful execution in two more cases, we have realized the credibility of this technique and hence would like to share our experience.

\section{TEChNIQUe}

Among our three cases, there were two adults and one child, for whom we have utilized this technique. Preoperative diagnostic flexible bronchoscopy was done in all the three cases. The CT scan thorax was done and thoroughly studied for preoperative planning and assessment.

All decisions for management of the cases were taken after coordination and planning with the anesthesiology team.

Informed and written consent were taken.

\section{Surgical Technique}

For this approach, the surgeon and assistant need to be positioned at head end. The patient would be supine with neck extended. After local infiltration of lignocaine, a 1-1.5 cm horizontal skin 
incision at the level of lower cervical tracheal ring was made. After dissection through the soft tissue, identification of tracheal rings, stay sutures were placed on both sides to maintain lateral traction. A vertical slit incision is then made through two or more tracheal rings. Maintaining traction pull with the help of the formerly reinforced ties, the slit is dilated with tracheal dilator and a $0^{\circ} 4 \mathrm{~mm}$ endoscope is introduced and advanced till the lesion is aptly visualized. With proper positioning of the patient and minimal mobilization of the trachea, the scope could be advanced as far as the terminal bronchioles, as was experienced in one of our cases. After securing the appropriately sized cuffed endotracheal tube (ET) under visualization by the $4 \mathrm{~mm}$ rigid $0^{\circ}$ endoscope, a fair working space could be achieved and the concerned pathology extirpated.

In every case, endotracheal intubation was performed with short-acting paralyzing agents.

\section{Case Descriptions}

We would like to share our experience with this technique as we discuss the three cases.

\section{Case 1}

The patient, a 55-year-old male, received as an emergency, was referred from another center with severe respiratory distress. Despite continuous effort, the patient's oxygen saturation was dropping by the moment. Prior radiology (CT thorax) revealed a round nodular lesion of approximately $20 \times 15 \mathrm{~mm}^{2}$ adherent to the left tracheal wall, about $2 \mathrm{~cm}$ above the carina, with no extraluminal extension (Fig. 1). Prior diagnostic bronchoscopy confirmed the low tracheal mass. The patient was initially planned to be transferred to a higher center having the facility of ECMO but was unable to do so because of unstable vitals. With a view to salvage the patient's condition, ETATS was planned. After proper planning with the anesthesiology team, the transcutaneous transtracheal endoscopic approach was undertaken as a desperate planned measure. This approach helped in securing the airway by guiding a 5 -mm-sized cuffed endotracheal tube beyond the mass (Fig. 2). After ensuring adequate oxygenation, the plane of anesthesia could be deepened. The mass was carefully dissected and completely excised. Hemostasis was achieved. The skin and subcutaneous tissue were finally closed in layers. The patient

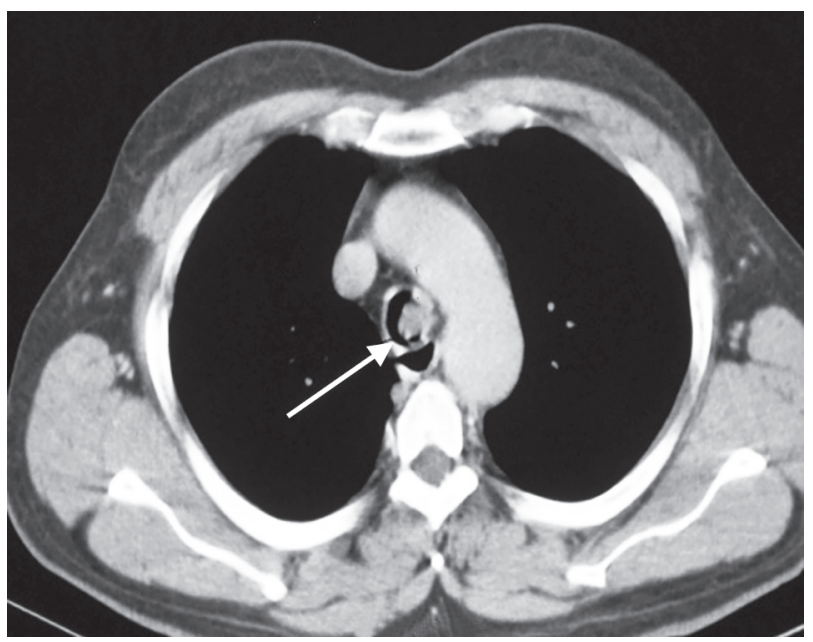

Fig. 1: An axial cut of CT thorax, revealing a round nodular lesion of approximately $20 \times 15 \mathrm{~mm}^{2}$, adherent to the left tracheal wall, about 2 $\mathrm{cm}$ above the carina, with no extraluminal extension was kept on a 7.5-mm-sized endotracheal tube and ventilator, and monitored closely. Extubation was carried out after 24 hours and was uneventful. The excised tissue, which was sent for HPE, revealed squamous cell carcinoma. The patient was then sent for chemoradiation. The patient had been followed till 6 months without any untoward event. Follow-up bronchoscopy at 6 months showed the tracheobronchial lumen to be free of disease (Fig. 3).

\section{Case 2}

The patient, a 65-year-old female, known case of COPD (bronchiectasis), was referred from another center because of persisting dyspnea. The patient had recent past history of hemoptysis for which he was receiving treatment in another center at the hands of a pulmonologist and interventional radiologist. The CT angiographic evaluation showed prominence of bronchial artery, for which bronchial artery embolization was done. Though hemoptysis subsided, dyspnea gradually increased. After receiving the patient in our center, a check X-ray chest revealed collapsed left lung with bronchiectatic changes. After initial stabilization, the patient was planned to be shifted to the operating theater (OT). On table, flexible bronchoscopy was done; a large clot was noted in the left main bronchus (Fig. 4). Clot evacuation by the endoscopic transtracheal approach was planned. Through a low cervical transcutaneous tracheotomy, a cuffed ET of appropriate size was initially placed in the right main bronchus ensuring one lung ventilation. The huge thick clot from left main bronchus extending to the upper and lower secondary bronchi was slowly dislodged and gradually evacuated by suction and forceps. The clot was dirty brown in color and was very resistant to suctioning (Fig. 5). With minimal mobilization of the trachea, the rigid bronchoscope could be well advanced up to the tertiary bronchioles and cleared of the pathology, which was not possible through the orotracheal route. The architecture of the evacuated clot resembled part of the bronchopulmonary tree (Figs 6 to 8). After maintaining hemostasis, the skin and subcutaneous tissue were closed in layers.

The evacuated material was sent for culture and HPE, which gave no extra information. Extubation was carried out after 24 hours and the patient was fit to be relieved from intensive care. The patient has been followed up till date, is doing well, with no episode of respiratory emergency since the surgery.

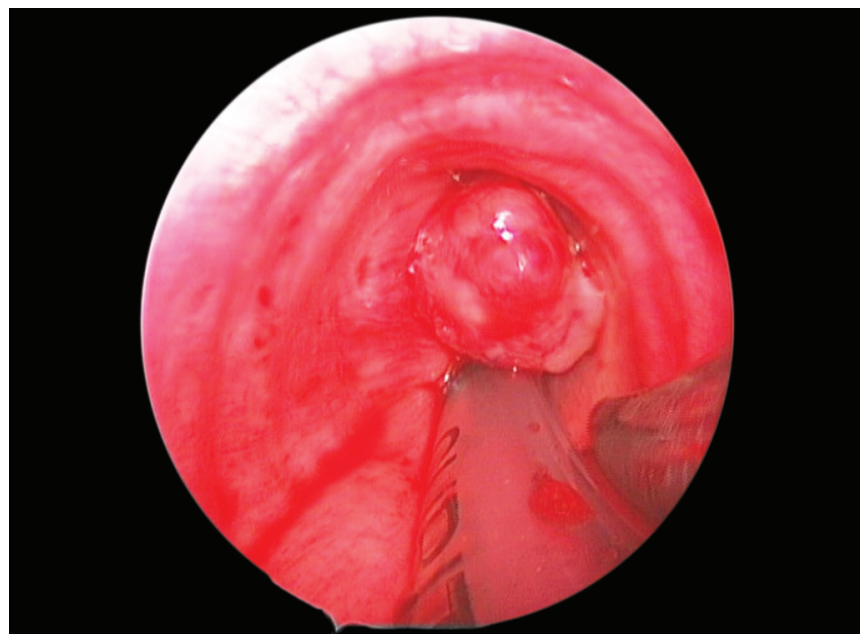

Fig. 2: Endoscopic view of the globular shaped tracheal mass, with the inflated cuffed end of the endotracheal tube secured beyond the mass 


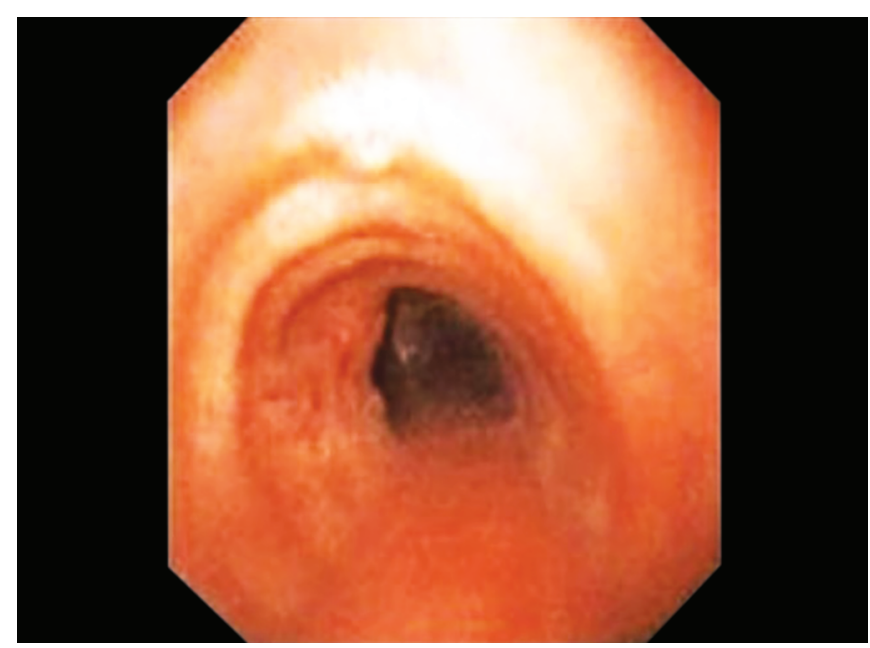

Fig. 3: Bronchoscopic picture at 6 months follow-up, showing the patent tracheobronchial lumen

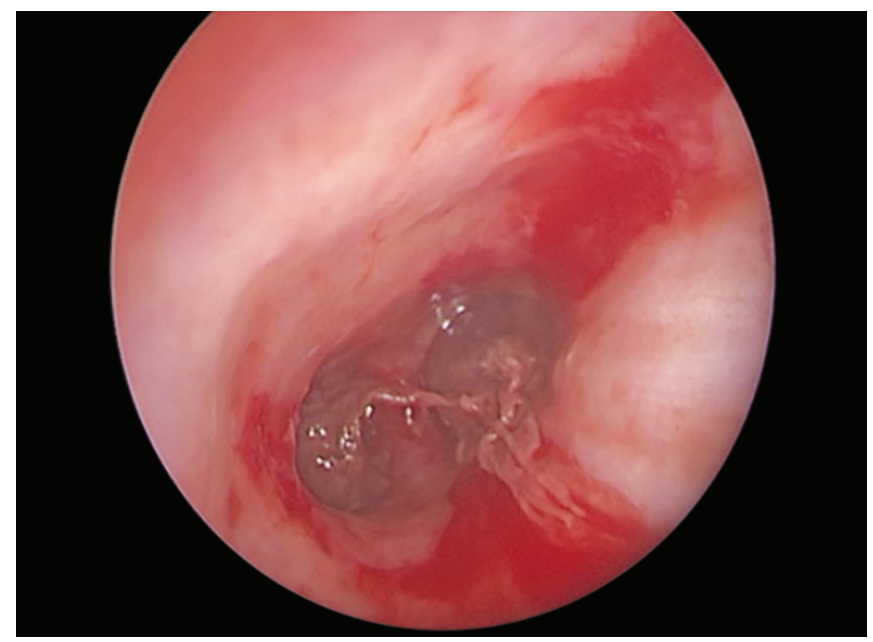

Fig. 5: Bronchoscopic picture showing the extension of the thick clot, as it was being dislodged and gradually evacuated by suction and forceps

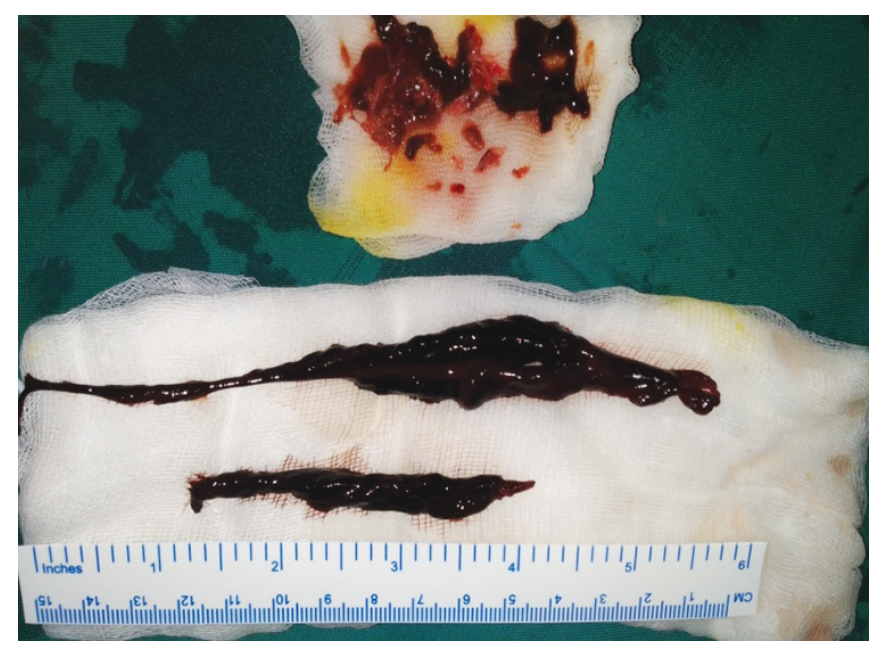

Fig. 7: Evacuated clot dimension

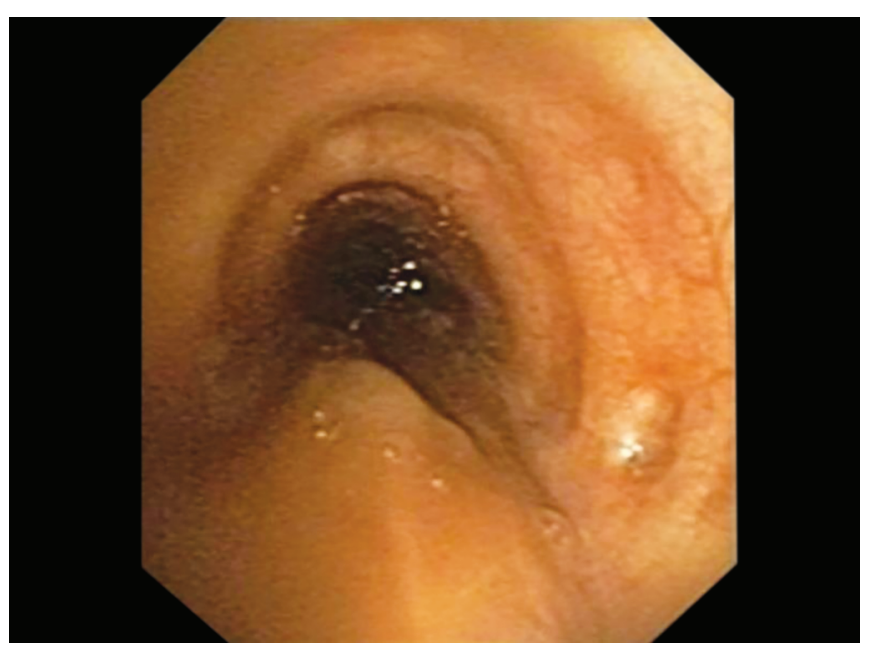

Fig. 4: Preoperative bronchoscopic picture, showing a large clot in the left main bronchus

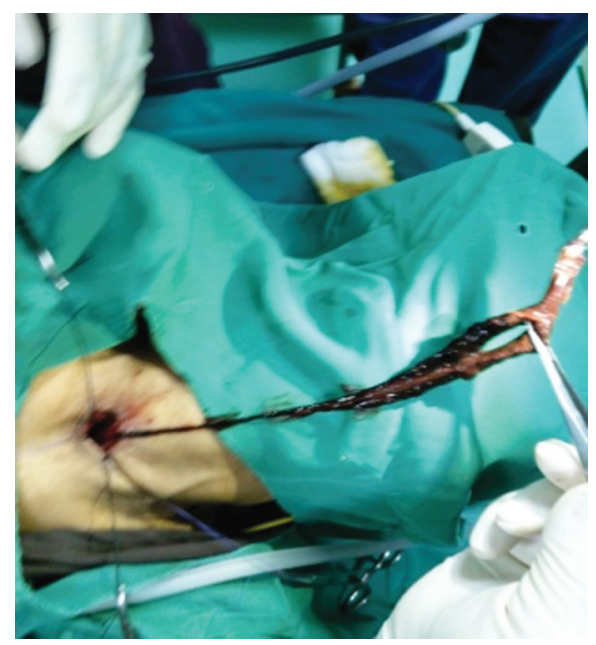

Fig. 6: Architecture of the evacuated clot, resembling part of bronchopulmonary tree

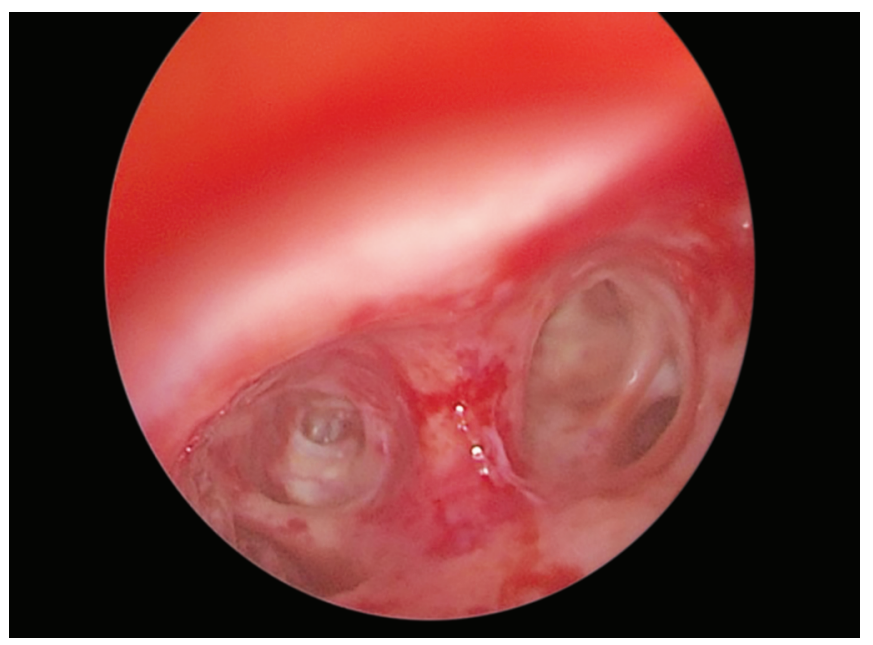

Fig. 8: On table bronchoscopic picture after evacuation of the clot 


\section{Case 3}

The patient, a 6-month-old male child, referred from periphery, presented with respiratory distress, cyanotic episodes on and off, polyphonic wheeze, and restricted air entry left side. The baby was undergoing treatment under the diagnosis of asthma. On diagnostic bronchoscopy, an ovoid mass was noted at the lower tracheal level obstructing $80 \%$ of tracheal lumen (Fig. 9). CT thorax revealed an intraluminal mass in thoracic trachea about $1.7 \mathrm{~cm}$ above the carina, with $2.1 \mathrm{~mm}$ patency of tracheal lumen (Fig. 10). The patient was planned for ETATS. Through the transcutaneous transtracheal approach, a difficult but successful cuffed endotracheal tube placement could be achieved beyond the mass, thus securing the airway (Figs 11 and 12). With the secured 4-mm cuffed endotracheal tube, and under visualization by a 4- $\mathrm{mm}$ rigid $0^{\circ}$ endoscope, a 3-mm working space could be achieved for extirpation of the pathology. The excided mass was sent for HPE. Hemostasis was maintained (Fig. 13). The skin and subcutaneous tissue were closed in layers. Immediate postoperative period was uneventful. Weaning from intensive care and intubation was accomplished by 24 hours.

The HPE report revealed it to be a hamartoma. Postoperative bronchoscopy at 6 months showed the tracheal lumen to be free

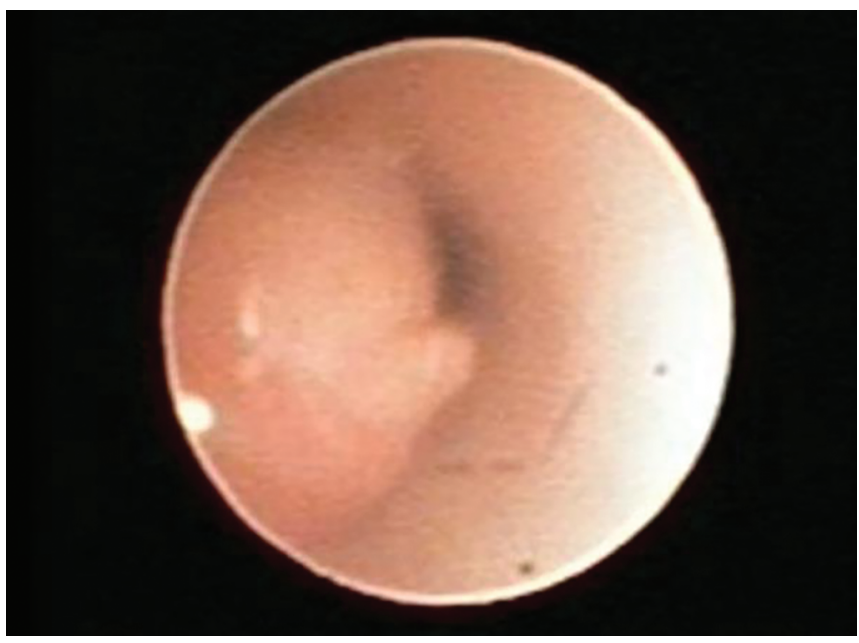

Fig. 9: Diagnostic bronchoscopic picture showing an ovoid mass in lower trachea, obstructing $80 \%$ of tracheal lumen

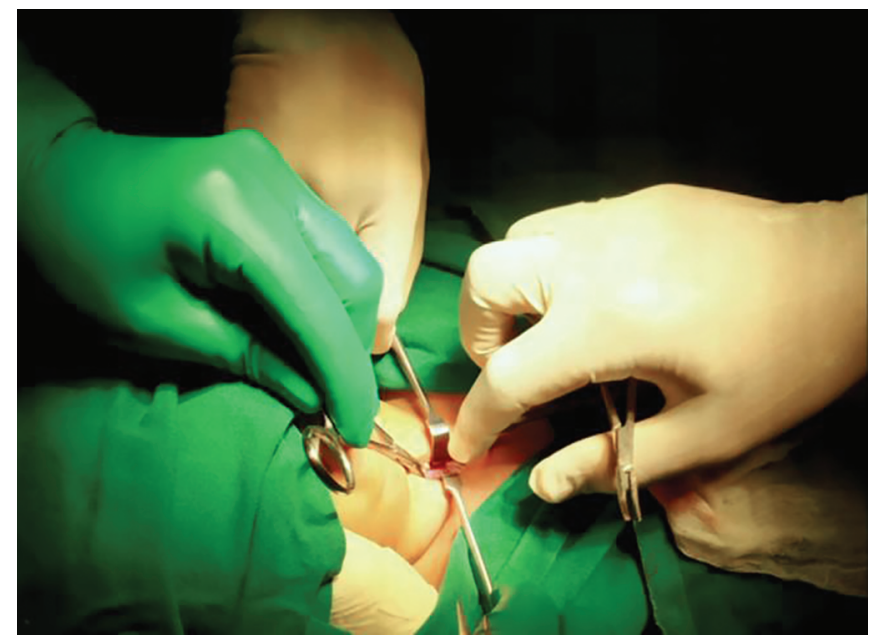

Fig. 11: Transcutaneous skin and tracheal incision of mass (Fig. 14). The child has been followed up till date and has been doing well.

No untoward postoperative event or complication related to the endoscopic transtracheal approach has been reported till date.

\section{Conclusion}

Most of the obstructive emergency airway cases with wheeze face the brunt of late diagnosis because of being treated as asthma.,13 Hence, a high index of suspicion and diagnostic bronchoscopy can save valuable time in the management of such cases. All our three patients have been received as emergency cases demanding prompt decision to salvage their condition. Diagnostic bronchoscopy and ETATS helped us manage the patients by helping to secure the airway beyond the pathology by cuffed endotracheal tube and by ensuring complete extrusion of the disease. ${ }^{9,10}$ of course, with the advent of extracorporal membrane oxygenation (ECMO), precious time can be bought for surgical management of airway emergency cases, while maintaining tissue oxygenation. ${ }^{14,15}$ But the unavailability of this advanced facility in most centers demands an alternate approach for such emergency airway cases, and we believe ETATS could come to the rescue. ${ }^{16}$

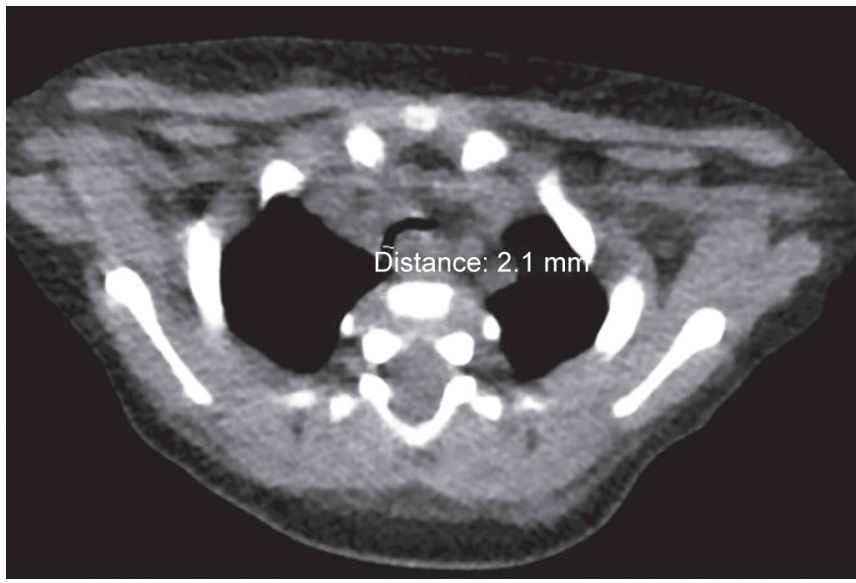

Fig. 10: An axial cut section of CT thorax, revealing the intraluminal mass, with $2.1 \mathrm{~mm}$ minimum tracheal lumen diameter patency

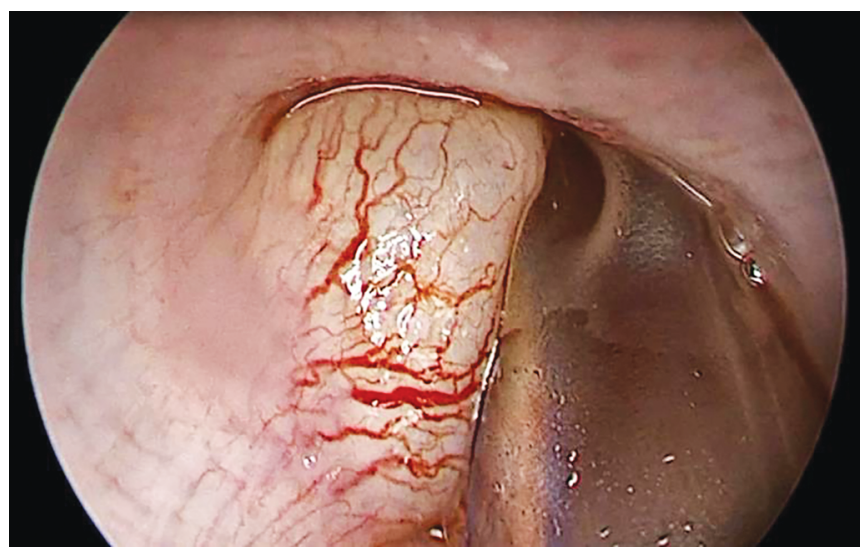

Fig. 12: Endoscopic view of the lesion, and securing the airway by positioning of the inflated cuffed end of the endotracheal tube beyond the mass 


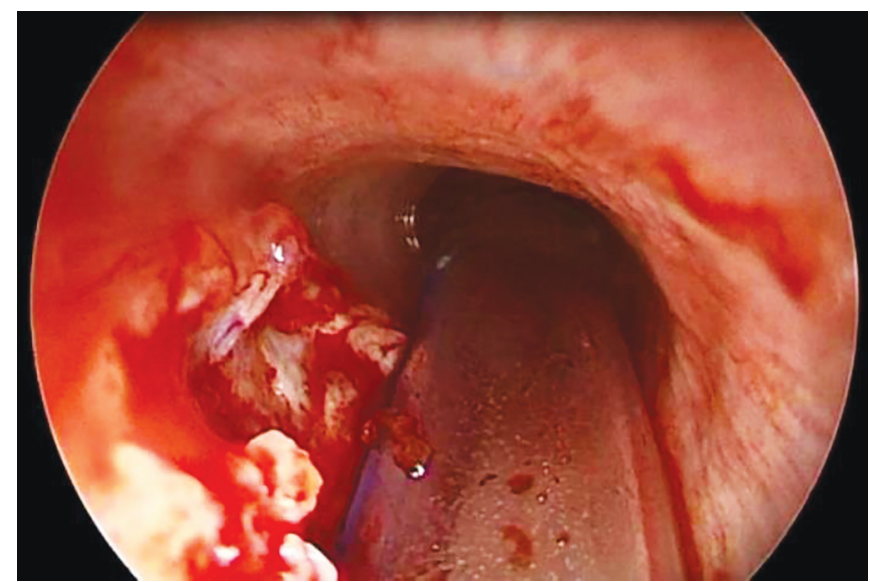

Fig. 13: Endoscopic picture after complete excision of the tracheal mass

\section{Clinical Significance}

The ETATS can be a savior in some difficult airway cases that might otherwise require radical approaches like thoracotomy. Needless to mention the cost-effectiveness of this approach. The ETATS can be safely conducted as a minimally invasive technique by a team of surgeons and anesthesiologists trained in airway surgery. The role of the anesthesiology team is, however, indispensable for the successful execution of ETATS. When tubeless anesthesia is not an option, the transcutaneous transtracheal endoscopic approach can prove to be a safe and useful option in surgical clearance of lesions or pathology limited to the tracheal or bronchial lumen as far as the terminal bronchioles, also facilitating a safe airway by cuffed ET. 3,11,12,17 Benign lesions or neoplasm, clot, foreign bodies limited to the tracheobronchial lumen, not easily accessible through the routine orotracheal route, could be accessed via the transtracheal route. Initial diagnostic bronchoscopy coupled with necessary radiological investigation is a prerequisite for case selection and execution of ETATS. ${ }^{7,18}$ Another advantage is postoperative weaning from intubation and intensive care within 24 hours, thus minimalizing the hospital stay and morbidity. No postoperative complication has been recorded in our cases till date. Hence, ETATS can provide a good approach for the management of difficult airway cases. 9,10,19 $^{2}$

\section{AcknOWLedgment}

We would like to convey our gratitude to Pratiksha Hospital, Guwahati, for providing us an excellent podium for necessary diagnostic and therapeutic interventions, without which our exploration with this novel surgical technique would not be possible.

\section{References}

1. Stoudemire WS, Muhlebach MS. Not all that wheezes is asthmaand not all are foreign bodies either! InC64. Pediatric case reports: airway diseases and bronchoscopy. Am Thora Soc 2018;201:A5586A5586.

2. Mineshita M, Slebos DJ. Bronchoscopic interventions for chronic obstructive pulmonary disease. Respirology 2014;19(8):1126-1137. DOI: $10.1111 /$ resp.12362.

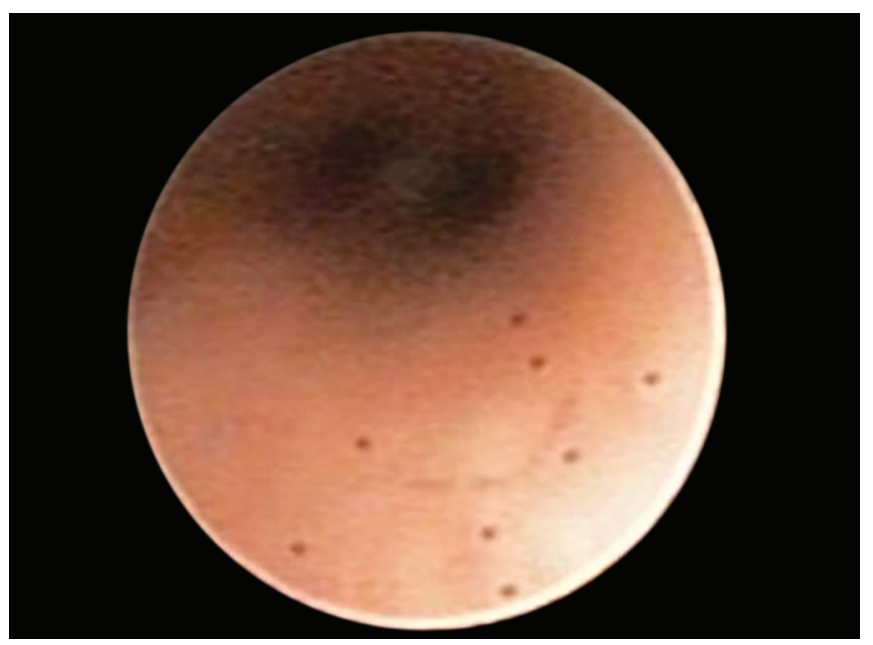

Fig. 14: Endoscopic picture at 6 months follow-up, the tracheal lumen is seen to be free of the pathology

3. Pearson $\mathrm{KL}$, McGuire $\mathrm{BE}$. Anaesthesia for laryngo-tracheal surgery, including tubeless field techniques. Bja Educat 2017;17(7):242-248. DOI: 10.1093/bjaed/mkx004.

4. Lathadevi HT, Guggarigoudar SP. Difficulties in management of a sessile subglottic polyp. J Clin Diagnos Res: JCDR 2015;9(12):MD01. DOI: 10.7860/JCDR/2015/15583.6911.

5. Smeltz AM, Bhatia M, Arora $\mathrm{H}$, et al. Anesthesia for resection and reconstruction of the trachea and carina. J Cardiothorac Vasc Anesth 2020;34(7):1902-1913. DOI: 10.1053/j.jvca.2019.10.004.

6. Goyal A, Tyagi I, Tewari P, et al. Management of difficult airway in intratracheal tumor surgery. BMC Ear Nose Throat Disord 2005;5(1):4. DOI: 10.1186/1472-6815-5-4.

7. Chen PT, Chang WK, Hsu WH, et al. Anesthetic management of a patient undergoing segmental resection of trachea with an endotracheal neurofibroma and nearly total occlusion of trachea. Acta Anaesthesiolog Taiwanica 2004;42(4):233-236.

8. Mathisen DJ, Morse C. Master Techniques in Surgery: Thoracic Surgery: Transplantation, Tracheal Resections, Mediastinal Tumors, Extended Thoracic Resections. Lippincott Williams \& Wilkins; 2014.

9. Reddy S, Swamy R, IRUGU DK, et al. Transtracheal endoscopic-assisted resection of a rare inflammatory myofibroblastic tumour in adult trachea: a case report. Acta Otorhinolaryngol Ital 2018;38(2):170.

10. Sharma SC, Devaraja K, Kairo A, et al. Percutaneous trans-tracheal endoscopic approach: a novel technique for the excision of benign lesions of thoracic trachea. J Laparoendosco Adv Surg Techni 2018;28(3):320-324. DOI: 10.1089/lap.2017.0224.

11. Paradis TJ, Dixon J, Tieu BH. The role of bronchoscopy in the diagnosis of airway disease. J Thorac Dis 2016;8(12):3826. DOI: 10.21037/ jtd.2016.12.68.

12. Prince JS, Duhamel DR, Levin DL, et al. Nonneoplastic lesions of the tracheobronchial wall: radiologic findings with bronchoscopic correlation. Radiographics 2002;22(suppl_1):S215-S230. DOI: 10.1148/ radiographics.22.suppl_1.g02oc02s215.

13. Alici IO, Kurt OK, Dursun $A B$, et al. Two cases of tracheal disease misdiagnosed as difficult-to-treat asthma. Respir Care 2013;58(11):e133-e137. DOI: 10.4187/respcare.02350.

14. Harris C, Cao C, Croce B, et al. Tracheal tumors. Ann Cardiothorac Surg 2018;7(2):317. DOI: 10.21037/acs.2018.02.02.

15. Malpas G, Hung O, Gilchrist A, et al. The use of extracorporeal membrane oxygenation in the anticipated difficult airway: a case report and systematic review. Can J Anesth/J Can d'anesthésie 2018;65(6):685-697. DOI: 10.1007/s12630-018-1099-x.

16. Patel RG. Percutaneous transtracheal jet ventilation: a safe, quick, and temporary way to provide oxygenation and ventilation when 
conventional methods are unsuccessful. Chest 1999;116(6):16891694. DOI: 10.1378/chest.116.6.1689.

17. Khaund G, Sarma N, Gogoi B, et al. Tracheal mass: a management challenge. Ann Indian Acad Otorhinolaryngol Head Neck Surg 2017;1(1):15.
18. Scarlata S, Fuso L, Lucantoni $G$, et al. The technique of endoscopic airway tumor treatment. J Thorac Dis 2017;9(8):2619. DOI: 10.21037/ jtd.2017.07.68.

19. Compeau CG, Keshavjee S. Management of tracheal neoplasms. Oncologist 1996;1(6):347-353. DOI: 10.1634/theoncologist.1-6-347. 